\title{
Clarice Lispector: escrita e silêncio
}

\section{Clarice Lispector: writing and silence}

RODRIGO MicheLL ARAUJO

\section{Resumo}

Este trabalho visa um estudo hermenêutico da problemática do silêncio na obra de Clarice Lispector, a partir de uma intersecção entre Filosofia e Literatura. Já evidenciado pela crítica ser o silêncio uma questão chave em sua obra (Benedito Nunes, 1989), tipificando uma inquieta e persistente busca pelo inexpressivo, nossa investigação situar-se-á nas "margens" que Clarice deslocou e fez delas o seu centro, demonstrando nelas os desdobramentos e as manifestações do silêncio, que se encontram com a própria escrita, mas que também conduzem a uma profunda e violenta confrontação com a própria autora.

Palavras-chave: Clarice Lispector. Silêncio. Escrita. Errâncias.

\section{Abstract}

This work aims at a hermeneutic study of the problem of silence in the work of Clarice Lispector, from an intersection between Philosophy and Literature. As has already been evidenced by critics, the theme of silence is a key issue in his work (Benedito Nunes, 1989), typifying a restless and persistent search for the expressionless, our investigation will be located on the "margins" that Clarice displaced and made them its center, demonstrating in them the developments and manifestations of silence, which are found in the writing itself, but which also lead to a deep and violent confrontation with the author herself.

Keywords: Clarice Lispector. Silence. Writing. Wanderings.

\footnotetext{
a Universidade do Porto, Porto, Portugal. Doutor em Filosofia, e-mail: rodrigo.literatura@gmail.com
} 


\section{Errâncias introdutórias}

Acreditamos que introduções são feitas de errâncias - palavra-ideia que tem importância capital neste trabalho - pelas margens. Lançamos, então, nossa pergunta de introdução: que pode o mergulho abismático, em Clarice Lispector, que não se contenta em apenas desvelar essa (outra) palavrasentimento que nos une em um pensar atlântico? No decorrer da obra de Clarice, acompanhamos diversas imersões através de narradores e protagonistas que se confundem e ao mesmo tempo arrastam o próprio leitor para os labirintos da subjetividade, formando aquilo que se faz fio condutor (enquanto "unidade") no corpus clariceano, que é a introspecção - um dos mais importantes vocábulos da obra de Clarice, além de ser um termo que preenche as principais páginas hermenêuticas de Benedito Nunes, um dos seus principais intérpretes.

Mas sejamos cautelosos. A introspecção, em Clarice, não se reduz a um recurso (o monólogo), já presente na sua “obra de estreia”² na cena literária, Perto do coração selvagem, que rapidamente tornou-se altitonante perante a crítica. Ela se traduz na própria "verdade" da autora - e independente do que entendamos (filosoficamente) por "verdade", acreditamos que não seja de todo despropositado destacar a ressonância kierkegaardiana presente no texto de Clarice (em diálogo com a chamada "filosofia da existência") 3 , quer dizer, aquilo que nos parece claro no pensamento do filósofo dinamarquês,

\footnotetext{
2 Mantemos as aspas por alguns motivos, que serão postos ao longo do texto. Aqui, a utilizamos para não esquecermos de alguns textos anteriormente publicados de maneira esparsa em jornais.

${ }^{3}$ Muito em voga na França do século XX, a filosofia da existência muitas vezes se confunde com o "existencialismo", de cariz sartreano, o que é um equívoco. Em linhas gerais, acompanhamos Jean Wahl que opta pela defesa do termo "filosofias da existência", que se apoia num "pensar existencial" tão antigo quanto o platonismo, podendo, assim, melhor agrupar autores distintos entre si - os chamados "filósofos da existência" de modo algum se identificaram como membros de uma "corrente" - como Kierkegaard, Nietzsche, o próprio Sartre e também Heidegger, que rejeitou sempre a etiqueta de "existencialista" (uma interpretação existencialista que acabou por ser um contrassenso no âmbito da recepção francesa). Para um melhor entendimento, sobretudo sobre a ambivalência homem/existência que está no centro da filosofia da existência, vale a leitura de As filosofias da existência, de Jean Wahl.
} 
que é a operação de uma deambulação interior como um “caminho" para uma "verdade essencial" 4 , impregnado, naturalmente, de um sentido religioso5. De algum modo podemos ouvir, mas sobretudo sentir, estas ressonâncias kierkegaardianas nas personagens de Clarice, que frequentemente encaram a fragilidade da vida a partir de um combate cheio de tensão, deixando escapar as "faíscas" pelas frestas. É justamente na tomada da existência enquanto “coisa frágil” que se manifesta um “querer" - da vida? De si? -, ou melhor, um desejo que, como diz Joana, "ainda não tem nome” (LISPECTOR, 1974, p. 66), mas que se traduz em imagens: numa espécie de estado de suspensão, num tempo deslocado do tempo - lembremos, por exemplo, de Joana, à beira da praia, mergulhando não no mar, mas em si mesma, logo após a morte do pai, anunciada já nos primeiros capítulos da obra -, a personagem recolhe-se no mais profundo da interioridade para lá encontrar qualquer "força vital” que lhe

\footnotetext{
${ }^{4}$ Pensamos sobretudo no Kierkegaard de Post-scriptum aux miettes philosophiques que, sob o pseudônimo de Johannes Climacus, distingue dois tipos de reflexão, a objetiva e a subjetiva. A reflexão objetiva "rend le sujet contingent et fait par là de l'existente quelque chose d'indifférent, d'éphémère" (KIERKEGAARD, 1949, p. 128), ou seja, correndo o risco de se cair em um pensamento abstrato em que o próprio indivíduo não está em primeiro plano. Já a reflexão subjetiva tem seu mérito justamente por poder dar acesso a uma espécie de verdade essencial, pois "la subjectivité, l'intériorité, est donc la vérité" (KIERKEGAARD, 1949, p. 137).

${ }^{5}$ Há na filosofia da existência de Kierkegaard uma dimensão profundamente religiosa que o próprio filósofo recebeu do pai, a partir de uma rígida educação, e que marcará toda sua obra. Aliás, há um consenso nos intérpretes de Kierkegaard em não dissociar o filósofo da figura paterna. O próprio Kierkegaard deixou muitos escritos onde retrata sua relação com o pai, de quem herda sua melancolia e os valores cristãos. Em Ponto de vista explicativo da minha obra de escritor, temos uma das mais emocionantes passagens sobre a formação de seu pensamento: "Estive, desde os meus verdes anos, sob a influência de uma imensa melancolia, cuja profundidade encontra a sua única expressão verdadeira na faculdade que me foi concedida com um igual imenso grau de a dissimular sob a aparência do bom humor e da alegria de viver; por mais longe que remontem as minhas lembranças, a minha única alegria foi a de que ninguém pôde descobrir como sentia infeliz; esta exacta correspondência (entre a minha melancolia e a minha virtuosidade em escondê-lo) mostra que estava destinado a viver para mim e para Deus. Criança, recebi uma educação cristã rigorosa e austera que foi, para perspectivas humanas, uma loucura. Desde a minha tenra infância, a minha confiança na vida quebrou-se pelas impressões a que sucumbira o próprio velho melancólico que mais tinha imposto [...]" (KIERKEGAARD, 2002, p. 82). Apesar de Kierkegaard ter experimentado em toda a vida a inquietação e a melancolia, nunca perdeu a fé, ou melhor, a paixão pela fé - aliás, "paixão" é um dos vocábulos de maior importância em seu pensamento; veja-se, por exemplo, este excerto da obra de 1843, Temor e tremor, publicada sob o pseudônimo de Johannes de Silentio, em "Elogio de Abraão": "conhecer a tristeza é humano, humano ainda é partilhar do desgosto dos aflitos, mas crer é mais reconfortante do que contemplar o crente" (KIERKEGAARD, 1959, p. 39).
} 
conduza a uma travessia daquilo que sofre no "eu finito" para se realizar no infinito ${ }^{6}$.

Esboçamos um argumento: se esta "suspensão" envia a personagem ao mergulho intimista é para deixar entrever aquilo que acreditamos ser uma paixão enquanto força vital do ser - e, mais uma vez, pensamos "com" Kierkegaard ${ }^{7}$-, que pode significar tanto o existente quanto a existência. Mesmo que essa "paixão" se encontre nas margens. Mas essas margens são o centro do mundo, ou melhor, do seu mundo. Quando falamos de Clarice, tratamos de uma autora que deixou o seu centro e procurou as margens mais “marginais" e fez delas o seu centro.

“Pensar Clarice” é partir em errância por "margens-centro”. É lá que suas personagens ${ }^{8}$ distanciam-se do mundo, por imersão, mas não para negálo - em prol de outro, melhor, como se afiança a crítica nietzschiana ao platonismo e ao cristianismo - mas tão somente para afirmá-lo. Não há qualquer tipo de fuga em Clarice - dessas, que se entrevê rastros de niilismo. Mas encontros. Com quem? Ou com o quê? A própria Joana responde: "tento isolar-me para encontrar a vida em si mesma" (LISPECTOR, 1974, p. 65). Há, portanto, uma necessidade de afastamento, até ao ponto de fazê-lo abertura para um encontro com o pulsar da vida. É preciso “desnascer” para nascer de novo, mais plena e luminosa, ou pelo menos desnascer até ao ponto líquido e úmido das Origens e lá se desdobrar e se refazer, sempre metamorfoseando-se.

\footnotetext{
${ }^{6}$ Neste momento, temos em mente o entendimento de Kierkegaard, em $O$ desespero humano (1961, p. 61), acerca do "eu" como uma síntese "consciente de infinito e de finito". Em Ponto de vista explicativo da minha obra de escritor, o filósofo afirma que é o "eu finito" que sofre, mas que busca "suprimir esta melancolia cujo sofrimento não me deixou livre, por assim dizer, um único dia". Continua, em seguida: "triunfar é vencer no sentido do infinito, o que, no sentido do finito, significa sofrer" (KIERKEGAARD, 2002, p. 83).

7 Outra ressonância kierkegaardiana: não foi o próprio filósofo que afirmou, nas íntimas páginas do Journal (1963, p. 243), que "la passion est en somme l'essentiel, c'est le vrai compteur des forces de l'homme"? Para uma leitura complementar, veja-se o ensaio "A escrita da paixão", de Benedito Nunes, que compõe a obra A clave do poético, onde o crítico interpreta a ideia de "paixão" no texto clariceano, passando, inclusive, por Kierkegaard (cf. NUNES, 2009, p. 218-222).

${ }^{8}$ Quanto à etimologia de "personagem", que pode ser admitida por ambos os gêneros, optamos pelo uso do feminino, acompanhando a mesma escolha feita pelo ensaísta Evando Nascimento, em Clarice Lispector: uma literatura pensante (2012, p. 33).
} 
Pulemos alguns hiatos para tentar chegar "mais perto" de Perto do coração selvagem. Tratamos até aqui de algumas errâncias sentidas no tecido textual de Clarice - sem ignorar as tantas outras que existem, ainda por fazerse. E se convocamos outros nomes para perto de nós foi tão somente para destacar, pelo menos, elo de cariz ontológico que os liga. Errância também percebida pela crítica, como é o caso de Benedito Nunes, que constitui uma crítica de interesse filosófico na obra de Clarice. Em O drama da linguagem (1989, p. 23-24) ${ }^{9}$, Nunes define a errância de Joana como uma "viagem sem destino e sem esperança, ao encontro de sua infância e de sua morte". Uma viagem "sem mapas"10, onde "origem" e "destino" não são exatos porque tudo é continuum. Mas junto do movimento de continuidade, esta representada pela ideia de fluxo (de consciência, mas também textual), também sobressai um outro, que é o de pausa, colocando no texto clariceano uma espécie de paradoxo que parece ser análogo aos inúmeros paradoxos da existência humana. Eis o destino de Joana: ser pausa - "isto é apenas uma pausa, a vida depois virá como uma onda de sangue, lavando-me" (LISPECTOR, 1974, p. 29) -, ou melhor, um intermédio, "intervalo entre ela e ela mesma" (LISPECTOR, 1974, p. 80).

Perto do coração selvagem, que pode ser lida como um laboratório experimental de temas ${ }^{11}$ que vão se desdobrar e se desenvolver nas obras posteriores, se emparceira da "errância-Bloom", herdando e assumindo para si as viagens passadas, mas apresentando aquilo que Evando Nascimento (2012, p. 110) chamou de "espaço de vacância", onde "os corpos se instalam sem fala, sem escrita, reverberando o branco de uma página por preencher".

\footnotetext{
${ }^{9}$ Os textos que compõem $O$ drama da linguagem: uma leitura de Clarice Lispector (1989), foram inicialmente publicados em 1973, em Leitura de Clarice Lispector, tendo sido escritos no ano anterior. Os dois últimos capítulos da obra, "O improviso ficcional" e "O jogo da identidade", foram escritos entre 1973 e 1982.

10 De modo semelhante, foi esta a viagem/errância empreendia pelo personagem Bloom, do poema épico Uma viagem à Índia, do poeta português Gonçalo M. Tavares, obra que supõe inúmeras viagens, mas que também não ignora as viagens passadas - veja-se no nome do personagem, tirado de James Joyce - em direção a uma Índia ainda e sempre prometida, um Eldorado, na busca de um "sentido" existencial.

${ }^{11}$ Veja-se, por exemplo, em "A mística ao revés em Clarice Lispector", de Luiz Costa Lima, a maneira como o crítico interpreta a personagem G. H. a partir de um conjunto de "dilemas" e "desenvolvimentos" que, de algum modo, formam uma "unidade" na obra de Clarice (cf. LIMA, 1969, p. 341).
} 
Enfim, uma "escrita com o silêncio, cheia de hiâncias e brancos, intervalos, reticências e, ao mesmo tempo, sussurros, gritos, falação" (NASCIMENTO, 2012, p. 110). Por isso, só em certa medida podemos encará-la como "obra de estreia" porque não se pode mensurar um "início" em Clarice. Tudo é continuação, fluxo. Como as reticências, presentes em quatro títulos de capítulo da primeira parte da obra e que, em Retórica, são chamadas de aposiópesis, isto é, o efeito de suspensão (de uma frase, de uma fala, de um pensamento) - detalhe importante que não pode ser desconsiderado pela crítica, pois as reticências são pistas, marcas do silêncio, mas também rastros da diaporese, isto é, da interrupção que o orador impõe a seu próprio discurso. Daí que elas nos conduzam à torrente do "desorganizável" - palavra-ideia que Clarice irá explorar em A paixão segundo G. H., mas já pressentida por Joana, mergulhada no desorganizável e no inconsciente que constituem, para ela, a própria "realidade", como vemos no seguinte excerto:

Fascinada mergulho o corpo no fundo do poço, calo todas as suas fontes e sonâmbula sigo por outro caminho. - Analisar instante por instante, perceber o núcleo de cada coisa feita de tempo ou de espaço. Possuir cada momento, ligar a consciência a eles, como pequenos filamentos quase imperceptíveis mas fortes. É a vida? Mesmo assim ela me escaparia. Outro modo de captá-la seria viver. Mas o sonho é mais completo que a realidade, esta me afoga na inconsciência (LISPECTOR, 1974, p. 65).

Aqui Clarice Lispector já deixa para sempre o "traço" incontornável de sua literatura, ou melhor, "o seu caminho pessoal e singular de acesso à ficção" (NUNES, 2009, p. 206). A busca pelo "núcleo de cada coisa". Um mergulho de outro tipo: aquele entrevisto por Silviano Santiago (2004, p. 233), no "rio que inaugura o seu próprio curso para, como a serpente uróboro, desaguar na nascente".

Nestas "errâncias" pelas "margens-centro" buscamos sobretudo demonstrar, com Perto do coração selvagem, um "novo tipo" de escrita que Clarice Lispector inaugura, em 1943, na cena literária brasileira, que mergulha, tal como a personagem Joana, nos pântanos da subjetividade e, banhada de 
águas muito antigas, entra num processo de renovação e continuidade ${ }^{12}$. Sua obra de "estreia" acaba por assumir para si o mesmo "efeito" do banho de Joana: um ritual iniciático sem precedentes e que, sem dúvida, deixou muitas marcas na Literatura Brasileira - estamos a pensar em Guimarães Rosa e seu Grande Sertão: Veredas, mas também no Catatau, de Paulo Leminski, e até nas Galáxias, de Haroldo de Campos.

\section{Errâncias pelo silêncio}

Das “margens-centro" podemos encontrar um tema caro à Clarice, que é o grotesco, por exemplo. Em um conto originalmente publicado em 1971, chamado "Perdoando Deus", em Felicidade Clandestina, a narradora, ao caminhar tranquilamente pela avenida Copacabana, no Rio, é surpreendida por um sentimento até então insólito: sentiu-se mãe de Deus, preenchida de amor materno sentiu-se também mãe da terra e do mundo (dos dois: pois em Clarice é no mundo que a terra se mostra - e não só). Mas imediatamente a personagem quase pisa em um rato morto, ali, coisa repugnante e morta diante de seus olhos. Ficou em pânico diante daquele grande rato ruivo de longa cauda: “Então era assim? eu andando pelo mundo sem pedir nada, sem precisar de nada, amando de puro amor inocente, e Deus a me mostrar o seu rato?" (LISPECTOR, 2016, p. 657), questiona a narradora. Aquele rato morto era uma "afronta", mas ao mesmo tempo causa o "impacto" necessário para um “impulso" que a leva a orquestrar uma vingança contra Deus, e que termina em conciliação - este conto se encontra também em uma edição póstuma de 1984, Para não esquecer, e vem com o título "A vingança e a reconciliação penosa".

Diante dessa cena grotesca, a personagem, ao caminhar, afirma o seguinte: “Ainda não percebera que na verdade não estava distraída, estava era de uma atenção sem esforço" (LISPECTOR, 2016, p. 654). A deambulação

\footnotetext{
${ }^{12}$ Esta característica singular e inédita de Clarice no panorama da literatura brasileira da época foi pressentida pelo crítico literário e ensaísta Antonio Candido (1989, p. 209), levandoo a afirmar ser este tipo de escrita a "origem das tendências desestruturantes" que manifestar-se-ão na cena literária posterior.
} 
da personagem por fragmentos do horrendo, em estado de "atenção sem esforço", nos oferece um material importante, pois se entendermos o lugar do grotesco como espaço ruidoso ${ }^{13}$, podemos interpretar este "grito" (interior) como uma manifestação do silêncio. Com isso, podemos considerar que em Clarice o silêncio exige sempre deslocamentos, trânsitos. É pelo silêncio que a autora se desloca justamente dos centros para as margens, para nelas as personagens terem um contato silencioso com este "grotesco".

$O$ contato silencioso com o grotesco permite à personagem identificar na natureza do rato a sua própria natureza, de maneira muito análoga à G. H. que, depois de uma longa repugnância em ver diante de si uma barata morta, sente que entre ela e o animal morto há uma espécie de elipse, dai que o "grotesco" avulta uma coloração existencial porque estas personagens querem comungar com o mundo, querem tocá-lo, senti-lo por fora, mas sobretudo por dentro, por isso G. H. não encontra outra solução senão sorver a barata morta junto com o caudal que a excede.

Insistimos na ideia de "margens que são centros" porque, enquanto centro, as personagens constantemente estão em contato com o ínfimo, resultando daí a relação de alteridade que atravessa sua obra. Mas os personagens de Clarice também estão sempre a uma distância da vida, há sempre uma elipse, há sempre um sentimento cultuado de "ainda não ter nascido" que perfila toda sua obra. Um "desnascer", mas que no fundo visa a um querer nascer - basta lembrarmos de Macabéa, uma personagem "nitidamente nula" ${ }^{14}$, mas, em alguns momentos, consciente de suas margens, quando vai à cartomante e lhe é revelado o seu destino (em seguida do cumprimento do destino). Por isso toda a obra de Clarice Lispector sempre

\footnotetext{
${ }^{13}$ Não é de nosso intuito aprofundar o debate acerca do grotesco em Clarice, mas tão somente nos apropriar de uma colocação de Olga de Sá, uma das mais prestigiadas intérpretes de Clarice Lispector, acerca do "espaço" que o grotesco ocupa no mundo moderno: "as representações do grotesco no mundo moderno constituem a oposição mais ruidosa e evidente a toda espécie de racionalismo e a qualquer sistema de pensar" (SÁ, 1993, p. 99).

${ }^{14}$ Apropriamo-nos livremente do título de um romance do escritor português Vergílio Ferreira, Nítido nulo, de 1971. Ressaltamos, para o leitor, as diferenças entre esta obra e o que estamos a discutir, embora acreditamos no estreito diálogo que, em determinados momentos, as obras de ambos os autores podem suscitar (cf. ARAUJO, 2016, p. 1-11).
} 
exige do leitor um mergulho "por inteiro", porque são muitas as "hiâncias" que sua obra supõe - e por "hiâncias" entendemos sempre as errâncias por entre os vazios, os hiatos, os abismos e os silêncios.

Se outrora afirmamos que o silêncio exige sempre deslocamentos, passamos agora para um segundo argumento, quer dizer, uma segunda manifestação do silêncio: a de que o silêncio, em Clarice Lispector, é um caminho para uma comunhão (i) com a existência; (ii) com o mundo; (iii) com Deus. Concentrar-nos-emos na obra Uma paixão segundo G. H.

A narradora, G. H., burguesa e dona de uma cobertura no Rio de Janeiro, transpõe uma situação banal em uma experiência-limite. A situação banal é a seguinte: após despedir sua empregada doméstica Janair, vai até ao "quarto de empregadas" com o afã de encontrá-lo sujo (pois assim devia de estar, já que se tratava de um espaço de "empregadas"), mas depara-se com o oposto. Ao entrar naquele cômodo, que faz parte de seu apartamento, mas ao mesmo tempo lhe é absolutamente indiferente, depara-se com uma barata que, num primeiro momento, por impulso, irá esmagar com a porta do guarda-roupa, deixando-lhe a metade para fora. A experiência-limite: segue-se, em forma de monólogo, um mergulho intimista da própria narradora diante da barata, que produzirá uma ação na narrativa.

G. H. trava uma luta consigo mesma para tentar "organizar" os fatos e narrar - a narrativa se desenvolve horas depois, numa manhã, posterior ao ocorrido. Desorganização que faz parte não apenas do universo da protagonista, mas é a própria singularidade da estrutura da obra, que começa e termina com seis travessões, ou seja, um fluxo, onde não há ponto de partida ou de chegada, tudo é continuum - recurso que Clarice explora em outras obras, como a vírgula que inicia Uma aprendizagem, ou o livro dos prazeres, dando corpo à fala da narradora-pintora de Água viva, quando revela para seu destinatário que "o que te escrevo não tem começo: é uma continuação" (LISPECTOR, 2015, p. 63).

G. H. fala de "desorganização" porque a experiência que vivera não foi “organizável”, por isso, sua busca (também a de Clarice?) é por uma palavra que possa exprimir em linguagem o inexpressivo. G. H. quer traduzir o silêncio, quer "traduzir o desconhecido para uma língua que desconheço" (LISPECTOR, 2013, p. 16). Mas, para isso, é preciso mergulhar no nada, ou naquilo a que 
chama de "neutro" e que define como o lugar do "inexpressivo". O neutro remonta à própria acepção latina do termo, "ne-uter", nem um, nem outro. $O$ neutro é uma suspensão. É quando o tempo se desloca do próprio tempo. É na suspensão que as personagens de Clarice veem a existência como esboço de contornos mal pintados. Na suspensão estas personagens querem perceber $\mathrm{O}$ mundo. E assim o fazem na dúvida, na suspeita, na interrogação.

É certo que o silêncio é uma possibilidade de abertura a esta suspensão, isto é, acesso ao neutro, segundo G. H. Aí o silêncio deixa de ser inexpressivo para se fazer "expressivo". G. H. faz do silêncio a sua expressão. O que possibilita uma conversa não apenas com a existência, mas com Deus e consigo mesma. Diz G. H.: "falar comigo e contigo está sendo mudo. Falar com o Deus é o que de mais mudo existe. Falar com as coisas, é mudo" (LISPECTOR, 2013, p. 126). G. H. comunga com o mundo (que é um aquém-horizonte), mas essa comunhão gera outra comunhão, para Deus (para um além-horizonte), isto pela via do silêncio.

Uma terceira dimensão do silêncio em Clarice diz respeito a uma metamorfose, isto é, um desdobramento. A imagem que G. H. utiliza para definir o silêncio, em $A$ paixão segundo $G$. H., é a seguinte: o silêncio é a respiração do mundo, "[...] a respiração contínua do mundo é aquilo que ouvimos e chamamos de silêncio" (LISPECTOR, 2013, p. 78). Respiração, mas também sopro, pulsação. Suas obras, de certo modo, se fundam no silêncio, mas deixam marcas no tecido textual. Mas também marcas no corpo, no pensamento. Poderíamos ler A Paixão segundo G. H. como um testemunho? Se por testemunho entendermos uma busca por organização dos fatos, mas sobretudo entendermos a palavra como um corpo, um "segundo corpo", podemos assim acompanhar a afirmação de Eugénia Vilela, em Silêncios Tangíveis, de que "o testemunho é nesse sentido o movimento de atravessar o mundo com a matéria do silêncio que a memória desloca no corpo, fazendo emergir um texto impossível" (VILELA, 2010, p. 440).

Em nossa investigação, buscamos "ler" os inúmeros silêncios que a obra de Clarice Lispector supõe como um "inexpressivo" que se converte em algo bastante "expressivo". De algum modo, damos continuidade à investigação já empreendida por Benedito Nunes, um dos críticos que, à época, melhor 
percebeu o silêncio em Clarice, desvelando suas implicações não apenas no tecido textual (estilo), mas sobretudo no próprio pensamento da autora, quando afirmou que a grande "busca" de Clarice foi decerto a "busca do inexpressivo" (NUNES, 1989, p. 67, grifo do autor). Também nós ${ }^{15}$ nos juntamos a uma plêiade de críticos e ensaístas que recorrem a uma hermenêutica filosófico-literária para buscar sempre novas interpretações deste que foi um grande interlocutor de Clarice, o silêncio. Pois, por fim, não acreditamos que o silêncio seja algo "secundário" em sua obra, como supôs Affonso Romano de Sant'Anna, no ensaio “Laços de família e A legião estrangeira", pertencentes ao volume Com Clarice, onde, ao tentar fazer um itinerário da fortuna crítica da autora, coloca o silêncio como questão marginal (cf. Sant'Anna, 2013, p. 96).

\section{Considerações finais}

Entendemos que o silêncio tenha sido uma das mais altas necessidades de Clarice Lispector, além de uma exigência da escrita, porque é no silêncio que ela se renova. Mas foi também no silêncio que se viu confrontada: com o “mundo", e também consigo mesma. Por isso acreditamos que sua obra é de algum modo um "texto impossível”, que quer dizer um testemunho poético, porque há um latente desejo de comunhão entre o corpo do sujeitopersonagem com o corpo do mundo. Lembremos que A Paixão segundo $G$. $H$. se inicia com uma tentativa, uma procura silenciosa, "estou procurando, estou procurando". Porque a própria obra e o pensamento da autora se fazem em constante procura daquilo que Clarice chamou por repetidas vezes, em Água viva, de "atrás do pensamento", isto é, o lugar que parece guardar a verdade do ser. Enfim, o lugar do neutro, do silêncio. Diz a narradora-pintora de Água viva: "no atrás do meu pensamento está a verdade que é a do mundo. A ilogicidade da natureza. Que silêncio" (LISPECTOR, 2015, p. 119).

\footnotetext{
${ }^{15}$ Em nossa tese de doutoramento, dedicada ao silêncio na poesia de Teixeira de Pascoaes, tivemos oportunidade de estabelecer algumas pontes com o silêncio em Clarice (cf. ARAUJO, 2020, p. 112).
} 
Ao se sentar, pondo a sua máquina de escrever em seu colo, a narradora de Água viva medita sobre o seu "atrás do pensamento", este estado onde o próprio silêncio se "estilhaça”, podendo assim ouvir de maneira mais íntima o bater de seu coração, mas também sentir um "nada vibrante".

O silêncio, enquanto um tema transdisciplinar, quase sempre tem assumido diversos contornos no espaço literário, podendo sugerir muitos caminhos, dos quais trilhamos apenas alguns. Talvez esse tenha sido um importante aprendizado que a nossa autora teve com o silêncio, perfilando-o em sua obra: o silêncio como reticências, quando o "inexpressivo" supõe (em nós, leitores) um grande horizonte de "expressividade”. E nada melhor, para uma tentativa de "conclusão" (porque Clarice nunca se conclui), que ficarmos com uma fala quase em tom testemunhal do narrador de Um sopro de vida (pulsações), obra publicada postumamente e que é quase inteiramente dedicada ao silêncio: "O que sinto não é traduzível. Eu me expresso melhor pelo silêncio" (LISPECTOR, 2012, p. 30).

\section{Referências}

ARAUJO, R. M. Vergílio Ferreira e Clarice Lispector: correspondências com o silêncio. Revista Pontes de Vista, Porto, v. 2, pp. 1-11, 2016.

ARAUJO, R. M. Silêncio e poesia em Teixeira de Pascoaes. 2020. 257p. Tese (Doutoramento em Filosofia) - Faculdade de Letras da Universidade do Porto, Portugal, 2020.

CANDIDO, A. A educação pela noite e outros ensaios. São Paulo: Ática, 1989.

KIERKEGAARD, S. Post-scriptum aux miettes philosophiques. 11. ${ }^{\text {a }}$ ed. Trad. Paul Petit. Paris: Gallimard, 1949.

KIERKEGAARD, S. Temor e tremor. Trad. Maria José Marinho. Lisboa: Guimarães Editores, 1959.

KIERKEGAARD, S. O desespero humano: doença até à morte. $5 \cdot{ }^{a}$ ed. Trad. Adolfo Casais Monteiro. Porto: Livraria Tavares Martins, 1961.

KIERKEGAARD, S. Journal (extraits): 1834-1846, tomo I. Trad. Knud Perlon; Jean-J. Gateau. Paris: Gallimard, 1963. 
KIERKEGAARD, S. Ponto de vista explicativo da minha obra de escritor. Trad. João Gama. Lisboa: Edições 70, 2002.

LIMA, L. C. Por que Literatura. Petrópolis: Vozes, 1969.

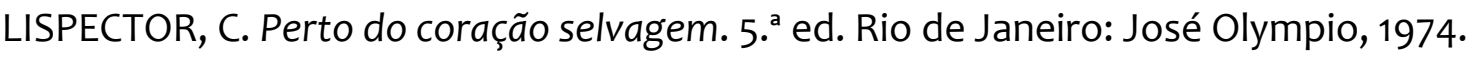

LISPECTOR, C. Um sopro de vida (pulsações). Lisboa: Relógio D’Água, 2012.

LISPECTOR, C. A paixão segundo G. H.. Lisboa: Relógio D’Água, 2013.

LISPECTOR, C. Água viva. Rio de Janeiro: Rocco, 2015.

LISPECTOR, C. Todos os contos. Org. Benjamim Moser. Rio de Janeiro: Rocco, 2016.

NASCIMENTO, E. Clarice Lispector: uma literatura pensante. Rio de Janeiro: Civilização Brasileira, 2012.

NUNES, B. O drama da linguagem. São Paulo: Ática, 1989.

NUNES, B. A clave do poético. São Paulo: Companhia das Letras, 2009.

SÁ, O. de. Clarice Lispector: a travessia do oposto. São Paulo: Annablume, 1993.

SANT'ANNA, A. R. de. Com Clarice. São Paulo: Editora Unesp, 2013.

SANTIAGO, S. O cosmopolitismo do pobre: crítica literária e crítica cultural. Belo Horizonte: Editora UFMG, 2004.

VILELA, E. Silêncios tangíveis. Porto: Afrontamentos, 2010. 